\title{
Uma Reflexão sobre o Processo de Avaliação das Pós-graduações Brasileiras com Ênfase na Área de Saúde Coletiva
}

\author{
LIGIA REGINA SANSIGOLO KERR-PONTES* \\ RICARDO JOSÉ SOARES PONTES *** $^{*}$ \\ MARIA LÚCIA MAGALHÃES BOSI ${ }^{\circ}$ \\ RAQUEL MARIA RIGOTTO ${ }^{\circ}$ \\ RAIMUNDA MAGALHÃES DA SILVA+ \\ JOSÉ GOMES BEZERRA FILHO ${ }^{++}$ \\ WARWICK ESTEVAM KERR ${ }^{*}$
}

Este artigo busca promover uma reflexão acerca dos critérios adotados pelo sistema de avaliação da Pós-graduação em curso no país e seu impacto no âmbito dos diferentes programas, conferindo destaque na análise à área de Saúde Coletiva. Ressalta-se, por um lado, a importância que os processos avaliativos têm na consolidação do sistema de ensino e pesquisa, contribuindo, de modo decisivo, para a promoção e monitoramento da sua qualidade. Em contrapartida, os autores convidam a uma reflexão sobre a concepção de ciência subjacente aos critérios adotados e seu impacto no conjunto dos cursos que compõem a pós-graduação em Saúde Coletiva. Para tanto, apontam obstáculos situados em planos distintos e as desigualdades, não apenas regionais, mas entre instituições geograficamente próximas mas que desenvolvem suas práticas em contextos distintos. O texto finaliza indagando sobre a correspondência entre o percurso histórico e os compromissos que marcam a trajetória da Saúde Coletiva e os rumos atuais da avaliação da pós-graduação nesse campo de saberes e práticas.

Palavras-chave: Avaliação, pós-graduação, ciência, Saúde Coletiva

Recebido em: 26/04/2005.

Aprovado em: 12/05/2005. 
Avaliação pode ser definida como um "processo sistemático para determinar até que ponto um programa ou intervenção atingiu os objetivos pretendidos" (SESSIONS, 2001). Essa definição pode ser aplicada à maioria das atividades desenvolvidas no campo da Saúde Coletiva, estruturando-se a partir de alguns componentes-chave que definem um processo bem-sucedido: objetivos e metas bem-definidos no programa a ser avaliado, um sistema estruturado e consistente para coletar, analisar e relatar as informações, um método claramente definido para medir o grau de mudança resultante do programa ou intervenção e um balanço para determinar se o objetivo final da avaliação foi alcançado.

Uma avaliação deve se propor a orientar as ações no setor a que se refere, determinar se as atividades do programa atendem aos objetivos declarados, se são apropriadas e se estão sendo efetivamente implementadas. Tomando-se essa perspectiva como ponto de partida, a avaliação de um programa pode permitir que os responsáveis pelas decisões meçam sistematicamente as atividades dos programas - neste caso, os de pósgraduação. Avaliar é, portanto, um processo tão importante quanto complexo, e demanda uma permanente reflexão para aperfeiçoá-lo e torná-lo uma ferramenta eficaz.

Deste modo cabe, logo de início, ressaltar o importante papel que a CAPES vem desempenhando no sentido da introdução, manutenção e incremento de um sistema de avaliação que vem contribuindo de forma decisiva para a consolidação - nos planos objetivo e subjetivo - de um processo permanente de avaliação dos programas de pós-graduação. Dificilmente algum pesquisador no país poderá sustentar que os cursos de pós-graduação não devam ser avaliados. Sabemos que esse processo, pode, em muito, contribuir para que os cursos aumentem e mantenham sua qualidade. Entretanto, os rumos que a avaliação dos cursos da pós-graduação vem tomando nos obrigam, agora, a fazer uma reflexão sobre a natureza dessa avaliação, seus objetivos e, sobretudo, quais as conseqüências e impactos do atual processo no futuro das pósgraduações brasileiras, especialmente nas regiões menos desenvolvidas ou em áreas mais vulneráveis.

A simples inspeção da divisão dos recursos da pesquisa nacional e do estatuto de "qualidade" conferido nas pontuações da CAPES já seria suficiente para explicitar a manutenção, na política adotada, do caráter excludente e reprodutor das históricas desigualdades regionais e institucionais como norma 
de conduta que acaba permeando o campo científico e a relação entre os "pares", embora essa "qualificação" e divisão de recursos se justifique em critérios que se pretendem rigorosos, neutros e, portanto, "de excelência".

Não se quer, aqui, questionar as instâncias e atores responsáveis pela elaboração desses critérios, mas urge uma reflexão sobre a concepção de ciência que norteia os referidos critérios, a realidade social à qual se vinculam e sobre o desenvolvimento científico proposto para o país, uma vez que a visão de ciência subjacente ao processo de avaliação levado a termo pela CAPES culminou no rebaixamento da nota de muitos cursos no país, no descredenciamento de outros, assim como na manutenção, num nível crítico, de uma grande quantidade de cursos.

Em recente carta, datada de 10 de janeiro de 2005, ao presidente da CAPES, um eminente cientista, primeiro pesquisador brasileiro a ser eleito para a American National Academy of Science, faz uma importante advertência, referindo-se ao processo de avaliação da CAPES de um curso da área básica do Instituto Nacional de Pesquisa da Amazônia (INPA). Diz ele:

"Permita-me apresentar umas considerações sobre Pós-graduação. São partes (ou início) de uma discussão que deveria ter sido feita antes. Os Cursos do INPA, inclusive o de Entomologia, considerado o melhor pelos especialistas de várias universidades, teve sua nota reduzida para quatro, quando todos esperávamos que fosse para seis... Perguntei: por que quatro? Resposta: por que o grupo de professores não tem publicações em revistas Qualis A.Internacional.

Como velho pesquisador que sou, acho que um critério restrito como esse tem, pelo menos, quatro defeitos, todos graves:

1) Não julga o mérito da pesquisa realizada publicada em revista Qualis B ou C. Cito um caso pessoal. Publiquei em 1970 um trabalho, que nos custou oito anos. Foi publicado (34 páginas) nos "Anais do $1^{\circ}$ Congresso Brasileiro de Apicultura (“Qualis zero”), em Florianópolis, Santa Catarina, páginas 151-185. Havia um pesquisador americano (Dr. Roger) no Congresso. Ele chamou a atenção dos cientistas americanos. A American National Academy of Science e o United States Department of Agriculture convidaram-me para ir aos Estados Unidos para traduzir o artigo. Não pude aceitar [...] naquele momento [...] porém indiquei para ir em meu lugar [...] um. brilhante aluno 
(Dr Leonel Gonçalves) [...] que traduziu o artigo que foi mimeografado pelo Departamento de Entomologia da Cornell University, N.Y, com 32 páginas, e entregue às Bibliotecas das Universidades americanas.

2) Nenhuma revista Qualis A de Matemática, de Estatística, de População aceitou publicar o famoso trabalho do Dr. Ronald Fisher, que mudou as análises estatísticas, incluindo-as nos conceitos de probabilidade. Um aluno leu, entendeu, entusiasmou-se e publicou-a numa revista de estudantes da Universidade de Edinburgh, na Escócia ('Qualis D’). Até hoje é o trabalho mais reproduzido da Escócia!

3) Baixa a qualidade competitiva de ótimos cursos (INPA, por exemplo) frente aos demais cursos apenas por um só item: 'publicações em revistas Qualis A'. Como um jovem pesquisador, recém-doutorado, vai ter três publicações em revistas Qualis A? Um curso de Genética de Jequié (BA) que poderia atrair os jovens do Nordeste foi recentemente rejeitado por essa razão.

4) Acho importante considerar que os cursos da USP, UFRJ, UFRGS, UFMG, se tivessem sido tão severamente julgados - sobretudo nos anos iniciais - não estariam contribuindo, como estão, para a ciência sulina. E com a nota quatro dada ao INPA (maior e melhor Instituto de Biologia Tropical, segundo várias declarações feitas pelo Dr. Harald Sioli, importante ecologista alemão) muitos alunos de Biologia irão prestar exames para cursos com melhores notas mas que não se comparam com o INPA, em oportunidades e conhecimento, especialmente agora que a FAPEAM está recebendo 1,7\% do governo (apenas a FAPESP vinha recebendo regularmente o $1 \%$ devido).

Essa ação contraria as decisões do governo de proteger o Norte e Nordeste com maiores verbas que evidentemente implicam ter mais e melhores cursos de pós-graduação. A proteção ao 'Sul maravilha' continua. Mas já sentimos o efeito de abaixar a nota da UFU para três: os melhores alunos estão prestando exames para Mestrado e Doutorado em outras Universidades, não por serem melhores, mas porque dizem que nota 3 não tem bolsa. É uma triste seleção capitalista" (KERR, W. E., 2005).

A situação referida nos parágrafos anteriores, que não se configura exclusiva do curso citado, mas de grande parte dos programas da área de Saúde Coletiva, daí a alusão ao documento, nos leva a refletir sobre algumas 
questões que precisam ser consideradas para tomarmos medidas propositivas - em lugar de punitivas ou excludentes. Tais medidas devem contribuir para o fortalecimento da adequada formação de recursos humanos qualificados, para uma produção do conhecimento no país que seja efetivamente voltada aos problemas da população nas diferentes áreas, assim como sua adequada divulgação em veículos de disseminação do conhecimento que não perpetuem as imensas desigualdades observadas no nosso país.

De início, constata-se que, de acordo com dados da CAPES (2005), $74,6 \%$ dos programas de todas as pós-graduações no Brasil localizam-se nas regiões Sul $(19,6 \%)$ e Sudeste $(55,0 \%)$ e, na área da Saúde Coletiva, esse quadro não se distingue significativamente: $71,4 \%$ (20/28) dos cursos existentes no país localizam-se nessas mesmas regiões. Metade de todos os cursos da área de Saúde Coletiva foi avaliada com nota três. Além disso, daqueles que se localizam nas regiões Nordeste ou Centro-Oeste, 75,0\% receberam nota três, contra 40,0\% dos localizados nas regiões Sul ou Sudeste. Diante desse quadro, preocupa-nos o futuro dessas pós-graduações. Verificar que as universidades mais atingidas, não por acaso, têm como características ter sua localização regional nas regiões menos desenvolvidas do país ou, mesmo se localizando em pólos mais desenvolvidos, por diversos motivos não conseguirem sair de baixos patamares de avaliação, evidencia uma forte carga desigual que o modelo de avaliação em curso está impingindo às pós-graduações.

Conforme já referido, uma das importantes áreas do processo avaliativo se concentra naquilo que se tem tornado quase que o único, ou pelo menos o mais importante, critério de avaliação do trabalho acadêmico, qual seja: a publicação científica segundo certos parâmetros, ao nosso ver, excessivamente pautados em uma ideologia cientificista, socialmente descontextualizados, difundidos mais recentemente no país em consonância com uma certa visão de mundo de parcela considerável da comunidade científica brasileira. Várias questões emergem ao se focalizar a temática e não serão aqui esgotadas. Contudo, podemos examinar algumas, dentre as quais, o acesso desigual dos pesquisadores brasileiros aos periódicos internacionais no momento da submissão do artigo. Obstáculos iniciais como o idioma, mesmo após o que se acredita ser uma boa tradução, podem ser citados como exemplo, que se agravam em certos segmentos do campo e subáreas do conhecimento - notadamente, no das Ciências Humanas em Saúde, onde barreiras referentes à simbolização e à linguagem ou, se preferirmos, culturais, inerentes aos objetos, dificultam certas 
transposições ao se trabalhar com material discursivo. Outro aspecto que merece ser considerado é em que medida essas revistas, que representam um pensamento e conhecimento tido como hegemônico, têm interesse em publicar aquilo que é produzido e contextualizado no Brasil. Isso evidentemente não pode ser compreendido de maneira mecânica como falta de qualidade intrínseca do texto submetido. E mais: no que e em que proporção esses veículos são efetivamente de melhor "qualidade" do que os periódicos nacionais da área? É preciso um refinamento de modo a caracterizar em que casos isso pode e deve ser sustentado.

No que diz respeito à apropriação social do saber científico, é oportuno lembrar que, não raro, o público externo à academia, a quem também se destina, ou deveria se destinar, a maior parte da produção intelectual do país - em especial, em áreas como a Saúde Coletiva - não tem acesso a esse material quando publicado no exterior ou o mesmo é restrito. Mas isso parece não contar ante o peso de outros parâmetros.

Uma das grandes bases internacionais de registro de revistas científicas é o Science Citation Index (SCI). Nela, cerca de 30,8\% dos periódicos são americanos, contra apenas $0,6 \%$ dos brasileiros. Essa base tem exigências bastante rígidas para que um periódico entre e permaneça em seus registros, dentre elas, a publicação rigorosa durante o ano e o pagamento de US\$10.000 anuais. Obstáculos nada desprezíveis para que periódicos procedentes do mundo "menos desenvolvido" consigam se manter nessa base. Se um periódico é excluído de uma base como esta, dificilmente consegue retornar, apesar de novas revistas de países desenvolvidos serem anunciadas e indexadas mesmo antes do lançamento de um número sequer.

Milhares de cientistas dos países periféricos apontam para obstáculos estruturais e preconceitos sutis que prejudicam a pesquisa realizada nas nações mais pobres em compartilhar suas descobertas com o mundo industrial, assim como com os demais (GIBBS, 1995). Em recente comunicado, o presidente da Academy of Science of South Africa explicita a dramática situação e os cenários que se apresentam para a consolidação de uma estrutura de pesquisa na região, ilustrando o que se passa em proporções distintas em muitas outras áreas (GEVERS, 2004).

No que se refere ao contexto brasileiro, algumas análises sobre o sistema de indexação nessas bases problematizam o modo como o mesmo sistema tem sido utilizado. Uma das considerações levantadas diz respeito ao prestígio 
assumido por determinadas bases mais conceituadas, que tem sido utilizado como parâmetro indicativo da qualidade de um periódico e, conseqüentemente, dos artigos publicados nos periódicos, mesmo se sabendo que a indexação bibliográfica não teve como objetivo avaliar a qualidade de revistas e, muito menos, de artigos. Contudo, parece ser este o entendimento e o uso que se faz desse sistema no interior do campo científico, e na Saúde Coletiva como subárea, gerando distorções como a "acirrada competição entre editores, autores e instituições financiadoras de pesquisa" em busca da acumulação de capital não apenas cultural/simbólico mas, como bem demonstrado nas análises de autores como Bourdieu (1983), do capital financeiro que a ele se associa.

A fetichização desses produtos leva a uma corrida desenfreada pelo maior número de artigos publicados, transladando para o processo de produção científica a lógica do trabalho industrial, apagando a dimensão ontológica inerente à produção de conhecimento que não se subjuga, em muitos domínios, à racionalidade prática funcional à produção tecnológica. Se em determinados segmentos do campo, essa racionalidade pode ser "produtiva", pensamos ser um equívoco medir com a mesma régua produções referentes a objetos ontologicamente distintos, exigindo, portanto, a consideração dos produtos em bases que respeitem sua diversidade e sua complexidade. Trata-se, portanto, de referenciar a discussão no conceito de eqüidade, questão ainda não contemplada a contento e que dista de ser simples, impondo alguns impasses que se revelam em questionamentos como o que se segue: o que "vale mais"? Ser o oitavo autor de um artigo Qualis A internacional ou a autoria única de um livro inaugural publicado por uma renomada editora nacional?

Prevalecendo a lógica quantitativista, se aprofundará a fragmentação dos objetos de conhecimento em partes, dificultando sua apreensão na totalidade, embora essa perda de "qualidade" seja considerada pelas agências que regulam o campo científico e por todos aqueles que pactuam com o modelo, como "produtividade". Urge, portanto, um exame criterioso do que está sendo entendido como qualidade - e não somente quantidade - do que tem sido produzido pelos programas na nossa área sob a égide dessa racionalidade, sobretudo em campos complexos como o da Saúde Coletiva cujas marcas de origem e desafios implicam qualidade de reflexão, sínteses ampliadas e não apenas (re)produção seriada.

Além desses aspectos, análises recentes têm apontado o quanto essa corrida vem afetando o processo de trabalho e a qualidade de vida dos pesquisadores, 
submetidos a uma rotina desgastante, que os leva a comprometer sua saúde, quando, no nosso caso, deveríamos promovê-la nos planos individual e coletivo.

Ao lado dos aspectos já apontados, cabe ainda assinalar que as demandas atuais subordinam os pesquisadores - em sua maioria também professores - a uma agenda de trabalho acadêmico que consideramos insuficiente ante os desafios e demandas do contexto científico e sociocultural do país, em geral, e de certas regiões, em particular. Para tornar-se competitivo no sistema CAPES, os pesquisadores, sobretudo aqueles que não dispõem de uma adequada infra-estrutura de pesquisa - situação freqüente nos programas novos - são obrigados a colocar em segundo plano atividades acadêmicas igualmente relevantes no plano científico e social, no cenário de um país pobre e desigual. Essa dimensão ganha relevo em universidades situadas no contexto onde as demandas da saúde pública estão longe da realidade dos países centrais do capitalismo mundial, e mesmo dos estados centrais do capitalismo brasileiro. Não seria igualmente importante medir-se, por exemplo, a relevância social de um programa, principalmente se localizado nas regiões menos privilegiadas socioeconomicamente ou a articulação dos mesmos com a formação em pesquisa em nível dos cursos de graduação?

Com efeito, parece haver alguns equívocos no que concerne à concepção de ciência, de conhecimento, de desenvolvimento científico e tecnológico, de difusão e transmissão do conhecimento, das tarefas concretas postas para a ciência nacional e particularmente para o sistema de instituições de ensino superior em suas diferentes realidades históricas e de desenvolvimento institucional e, portanto, no modelo de avaliação vigente para os cursos de pósgraduação do país, segundo os critérios CAPES.

Evidentemente, isso não se dá no abstrato, mas no seio de relações concretas no espaço da rede que conforma o campo científico, hierarquizado, sob a égide de uma certa concepção de ciência, ainda hegemônica, partilhada por um conjunto de pesquisadores que tradicionalmente vem mantendo, por mecanismos diversos, sua hegemonia nesse campo. Esses setores construíram uma sólida base - material e simbólica - na chamada comunidade científica, influenciando áreas tradicionalmente mais afins com uma tradição crítica, como é o caso da Saúde Coletiva - porque, lembrando Bourdieu .(1983; 1998), o modelo é funcional para os de cima, já que favorece a acumulação do capital científico sob o prisma da dominação política e do acesso ao financiamento da pesquisa. 
Tal hegemonia se funda, em parte, no pressuposto da existência de uma comunidade científica nacional e internacional homogênea e abstrata, de uma ciência neutra e a serviço de si mesma - traços da ideologia cientificista (CHAUÍ, 1997) que permeia as relações no campo - supondo, ainda, que as revistas científicas, nacionais ou internacionais, estão a serviço dessa comunidade científica abstrata, sob o prisma exclusivo de critérios de qualidade e de excelência.

Apagam-se, assim, as diferenças, comprometendo o processo avaliativo nos planos técnico e ético. Seria possível sustentar que formar um doutor numa região como Norte ou Nordeste é tão fácil como formá-lo nas regiões Sul ou Sudeste? É justo comparar um curso desenvolvido por um pequeno grupo de professores que ministra paralelamente às suas atividades de pesquisa e ensino em nível de pós-graduação uma dezena de disciplinas de graduação e estágios com outros cursos nos quais a articulação com a graduação é muito fraca ou mesmo inexistente?

Acreditamos que uma avaliação válida não pode deixar de contemplar esses dentre muitos aspectos que, em breve, se não considerados, responderão pelo esfacelamento da pós - ao menos na nossa área - caso a racionalidade atual não seja revista em prol de ações mais solidárias que contribuam para a consolidação da área em seu conjunto, em lugar de uma hierarquização interna, bastante perigosa ante os cenários que se apresentam e onde ressaltam graves problemas estruturais. Um exemplo é a dificuldade de desconcentrar os cursos: como ampliar o corpo permanente dos programas externos ao eixo Sul-Sudeste? Mesmo com a existência de programas para fixação de professores e pesquisadores nas regiões Norte e ou Nordeste, iniciativa, sem dúvida alguma elogiável, observam-se as enormes dificuldades em se levá-los para lá ou mesmo de manter os profissionais nessas regiões. Os incentivos financeiros não são suficientes para atrair pesquisadores experientes e, muito menos, competir com o mercado privado, além de o sistema avaliativo desfavorecer a acumulação do capital científico e, por conseguinte, financeiro, conforme já apontado.

Em síntese, procuramos demonstrar a inexistência de uma comunidade científica homogênea, nos planos nacional e internacional, por razões políticas, ideológicas e sociais, esta última determinando as condições de possibilidade colocadas pela realidade como problemas científicos e dos meios para estudálos e divulgá-los. Muitos pensam, como Bertold Brecht, que "o verdadeiro papel da ciência é diminuir o sofrimento da humanidade". Mas muitos outros defendem 
claramente que o verdadeiro papel da ciência é fornecer o conhecimento científico e técnico para alavancar o poder industrial do capitalismo moderno.

A doutrina incorporada pelas CAPES pode vir a reforçar uma tendência perniciosa na pós-graduação no Brasil, que poderia não ser tão ambiciosa em qualquer das duas polaridades, entre o capital e a humanidade. Essa tendência tem colocado, como verdadeiro papel desta "ciência", conforme já reiterado neste texto, publicar muito, mesmo que com artifícios questionáveis e escassa relevância para o contexto social de origem, em revistas preferencialmente estrangeiras, ou em revistas nacionais, mas preferencialmente em língua estrangeira, buscando assim, de maneira talvez demasiado exclusiva, visibilidade e projeção "acadêmica" a seus supostos "cientistas".

Será que todo esse empenho tem valido a pena ou deveríamos também contemplar outros aspectos em nossos esforços, recuperando a trajetória e os compromissos históricos (NUNES, 1988) que demarcaram a área da Saúde Coletiva?

\section{Referências}

BOURDIEU, P. O campo científico. In: ORTIZ, R. (Org.). Pierre Bourdieu. São Paulo: Ática, 1983. p. 122-155.

BOURDIEU, P. Os pesquisadores, a ciência econômica e o movimento social. In: _. Contrafogos: táticas para enfrentar a invasão neoliberal. Rio de Janeiro: J. Zahar, 1998. p. 71-79.

CHAUÍ, M. O ideal científico e a razão instrumental. In: Convite à filosofia. São Paulo: Àtica, 1997. p. 278-286.

COIMBRA JR., C. E. A. produção científica em saúde pública e as bases bibliográficas internacionais. Cadernos de Saúde Pública, Rio de Janeiro, v.15, n.4, p.883-888, out./dez. 1999.

GEVERS, W. Action now. TWAS Newsletter, Trieste, v. 16, n. 3/4, 2004.

GIBBS, W. W. Lost science in the third world. Scientific American, New York, p. 92-99, 1995. Disponível em: <http://www.capes.gov.br>. Acesso em: 11 abr. 2005.

KERR, W. E. Comunicação pessoal. 2005. Mimeo. 
NUNES, E. D. A medicina social no Brasil: um estudo de sua trajetória. Estudos de Saúde Coletiva, Rio de Janeiro, n. 5, p. 97-111, 1988.

SESSIONS, G. Avaliação em HIV/AIDS: uma perspectiva internacional. FUNDAMENTOS de Avaliação. Rio de Janeiro: ABIA, 2001. (Coleção ABIA n. 2).

\section{NOTAS}

* Professor Adjunto IV, Departamento de Saúde Comunitária da Faculdade de Medicina, Universidade Federal do Ceará. R: Prof Costa Mendes, 1.608/5 andar - Rodolfo Teófilo. CEP: 60.970-140 - Fortaleza - CE. Fone/fax: (85) 4009-8045. Endereço eletrônico: ligia@ ufc.br.

** Professor Adjunto IV, Departamento de Saúde Comunitária da Faculdade de Medicina, Universidade Federal do Ceará. Endereço eletrônico: rjpontes@ fortalnet.com.br.

• Professor Adjunto IV, Núcleo Estudos em Saúde Coletiva, Universidade Federal do Rio de Janeiro. Endereço eletrônico: malubosi@nesc.ufrj.br.

${ }^{\circ}$ Professor Adjunto IV, Departamento de Saúde Comunitária da Faculdade de Medicina, Universidade Federal do Ceará. Endereço eletrônico: raquelrigotto@ hotmail.com.

+ Professora Titular, Centro de Ciências da Saúde, Universidade de Fortaleza. Endereço eletrônico: rmsilva@unifor.br.

++ Professor Adjunto IV, Departamento de Saúde Comunitária da Faculdade de Medicina, Universidade Federal do Ceará. Endereço eletrônico: gomes@ufc.br.

\# Professor Titular, Departamento de Biociências, Universidade Federal de Uberlândia, Campus Umuarama. Endereço eletrônico: kerr@ufu.br. 


\section{ABSTRACT}

\section{Reflections on the Evaluation of Brazilian Graduate Studies with an Emphasis on the Collective Health Field}

This article aims to reflect on the criteria used in the current evaluation of graduate studies in Brazil and their impact on different programs, highlighting the analysis of the Collective Health field. The article emphasizes, on the one hand, the importance of evaluation processes for consolidating the teaching and research system, contributing decisively to the promotion and monitoring of its quality. On the other, the authors invite readers to reflect on the underlying concept of science in these criteria and their impact on the set of courses comprising Collective Health graduate studies in the country. The authors thus point to the obstacles on various levels and the inequalities between regions and between institutions that are geographically close, but which develop their practices in distinct contexts. The article concludes by inquiring as to the correspondence between the historical background and the commitments marking the history of Collective health and the current directions in the evaluation of graduate studies in this field of knowledge and practice.

Key words: Evaluation; graduate studies; science; Collective health. 